\title{
Removal of the radionuclides from aqueous solutions by biosorption on the roots of the dandelion (Taraxacum officinale)
}

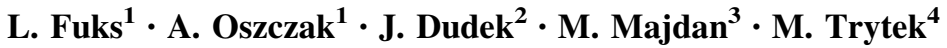

Received: 15 October 2015/Revised: 10 March 2016/ Accepted: 29 June 2016/Published online: 19 July 2016

(C) Islamic Azad University (IAU) 2016

\begin{abstract}
A novel biosorbent-dandelion root (DRB)was investigated as adsorbent for removal of $\mathrm{Sr}(\mathrm{II})$ and Am(III) from aqueous solutions. Batch equilibrium experiments were carried out to study the effect of contact time, initial concentration of the metal and $\mathrm{pH}$ of the media as well as of the sorbent amount. The equilibrium time was found to be $90 \mathrm{~min}$ for adsorption of both radionuclides. The kinetic model can be described by the pseudo-secondorder model well, and the isotherm model is fitted to Freundlich model the best. The maximum adsorption capacity of the DRB at pH about 6.0 was calculated to be 63.7 and $80.6 \mathrm{~g} \mathrm{~kg}^{-1}$ for $\mathrm{Sr}(\mathrm{II})$ and $\mathrm{Eu}(\mathrm{III})$, respectively. About $90 \%$ of $\mathrm{Am}(\mathrm{III})$ and $80 \%$ of $\mathrm{Sr}(\mathrm{II})$ were removed when $30 \mathrm{mg}$ of the biosorbent was used in $1 \mathrm{~mL}$ of the solution. Use of the sequential portions of the fresh sorbent is expected to increase efficiency of the process. Complexation of $\mathrm{Sr}(\mathrm{II})$ and $\mathrm{Am}$ (III) by strong chelating agents, e.g., citrate, oxalate and EDTA, did not diminish significantly the sorption efficiency of the sorbent. Once sorbed, $<1 \%$ of each radionuclide was desorbed by water.
\end{abstract}

L. Fuks

leon.ichtj@gmail.com

1 Centre of Radiochemistry and Nuclear Chemistry, Institute of Nuclear Chemistry and Technology, Dorodna 16, 03-195 Warsaw, Poland

2 Laboratory of Nuclear Analytical Methods, Institute of Nuclear Chemistry and Technology, Dorodna 16, 03-195 Warsaw, Poland

3 Faculty of Chemistry, Maria Curie-Skłodowska University, M. C. Sklodowska Sq. 2, 20-031 Lublin, Poland

4 Department of Industrial Microbiology, Institute of Microbiology and Biotechnology, Maria Curie-Skłodowska University, Akademicka St. 19, 20-033 Lublin, Poland
Graphical Abstract Low-cost biomass obtained from the dandelions' roots (DRB) was investigated as adsorbent for removal of strontium and americium from aqueous solutions.

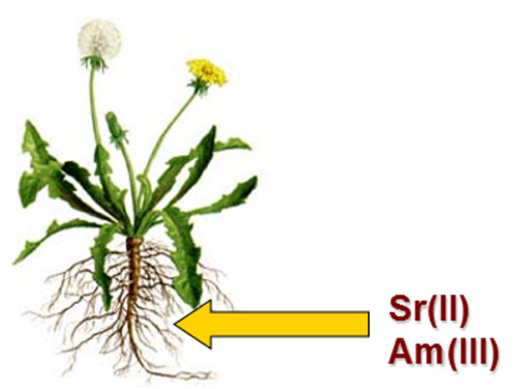

Keywords Americium-241 · Aqueous contaminated solutions · Dandelion root · Isotherms · Metal ions biosorption - Radioactive wastes - Radionuclides · Strontium-85

\section{Introduction}

Industrial and agricultural work involves the use of many different chemicals that can pollute water. The main contaminants include toxic metals, and their content in water growths in the environment as the result of human activity. Global emission of selected toxic metals in years 1850-1990 increased from 500 times (copper) to 3500 times (zinc) (Järup 2003). So, development of methods for the removal/recovery of these toxic metals, precious metals, and metallic radionuclides from aqueous solutions are of particular importance. The most frequently used 
methods involve chemical precipitation, chemical and electro coagulation, filtration, ion exchange, electrochemical treatment, membrane technologies, and adsorption (Crittenden et al. 2012; Gupta et al. 2012). However, most of these are inefficient and/or produce large quantities of sludge which must be treated or stored with care. Simultaneously, ion exchange and membrane or activated carbon adsorption procedures are extremely expensive when treating large amounts of water containing toxic metals in low concentrations (e.g., Dhir 2014). Therefore, the development and implementation of alternative, preferably low cost, separation technologies are crucial to improve water decontamination operations. Among such technologies is biosorption, a process based on the passive cation binding by dead or living biomass (Schiewer 1995).

Biosorption could be applied as the superior method for the metal recovery in the concentrations below $100 \mathrm{mg} \mathrm{L}^{-1}$, where other techniques are ineffective or costly (Schiewer 1995; Imran 2012; Fomina and Gadd 2014). Among the most frequently used biosorbents, currently used industrial metal-bearing effluents are fungi, algae, or different bacteria.

Roots of the common perennial weed dandelion (Taraxacum officinale) contain inulin (Schütz et al. 2006), a starch-like polysaccharide that may have medicinal properties as well as a metal complexing capacity. The content of inulin in dandelion roots ranges from $2 \%$ in spring to $40 \%$ in autumn (Bisset et al. 1994). It is a linear fructose polymer built from 2 to 60 D-fructose units connected through $\beta(2 \rightarrow 1)$ glycosidic linkages with a terminal $\alpha(1 \rightarrow 2$ )-bonded D-glucose (Nair et al. 2010; Niness 1999). Low molecular weight inulin polymers, i.e., with $<10$ fructose units, are often referred to as fructooligosaccharides (FOS) (Niness 1999). The compound found in many herbs is a mixture of polymers with different degrees of polymerization (DP) containing 2-50 fructose units (Yildiz 2011). In addition to inulin, dandelions provide another desirable product: rubber. This is why these robust and undemanding plants have become the focus of attention of the rubber-producing industry, and we may expect a great increase in dandelion industrial production accompanied by further decrease in its low price.

A major increase in the use of radioactive materials for nuclear energy production as well as in science, nuclear medicine, and industry raises the demand for novel methods of concentration and solidification of large volumes of contaminated aqueous solutions. Besides certain inorganic and organic sorbents (e.g., zeolites and clays, Wofatite or Amberlite, respectively), different materials of biological origin have been tested. To our knowledge, neither inulin nor the whole dandelion root has been tested as a potential sorbent of radioactive metals from wastewater. In the present study, powdered dandelion root was tested as a low cost, renewable, and reusable sorbent for radionuclides.

The radionuclides studied in the present work were strontium-85 (Sr-85) and americium-241 (Am-241). The former was used as a surrogate for strontium-90 (Sr-90), a radionuclide that is difficult to detect. $\mathrm{Sr}-90$ is a by-product of fission reactions within nuclear reactors. Because of its high decay energy and long half-life of 30 years, it remains hazardous for several centuries. The radionuclide deposits in bone and bone marrow, so exposure from contaminated food and water, are linked to bone cancer and leukemia (e.g., EPA-Strontium Web site, http://tinyurl.com/ye5y6g4). It has already been found that common freshwater green algae sequester strontium into insoluble crystals, offering a possible way to separate Sr-90 from less hazardous components of nuclear waste (Krejci et al. 2011).

Am-241 may be released into the environment from nuclear reactors, nuclear explosions, and accidents, as well as from manufacturing products containing americium (e.g., smoke detectors). A typical household smoke detector contains $33 \mathrm{kBq}\left(3 \times 10^{-4} \mathrm{mg}\right)$ of Am-241. Am-241 is also used for industrial gauging applications and in medical diagnostic devices. Because Am-241 has a long half-life (more than 430 years), it may pose a long-term environmental hazard.

The present study is aimed to examine the possibility of using natural material containing inulin as a low-cost alternative adsorbent for the metallic radionuclides from the aqueous wastes. Novelty of the sorbent is its relatively big content of the fructose (i.e., pentose), in contrast to currently used materials which comprise hexoses. The effects of the contact time, acidity of the purified solution, initial metal concentration, and the presence of the complexing agents on the metal adsorption were investigated. Characterization of the sorbent was exercised by the SEM method, FT-IR spectroscopy, and its thermal decomposition was examined. Adsorption isotherms and kinetic parameters were also calculated and reported. Moreover, Am(III) and $\mathrm{Sr}$ (II) adsorption capacity of the proposed sorbent and certain other adsorbents was compared on the basis of the literature data.

\section{Materials and methods}

Five grams samples of the dandelion roots (medical material, "Kawon-Wholesale", Gostyn, Poland) were ground in a bead mill and homogenized for $2 \mathrm{~h}$ in the rotating drum. After that, the powdered solid material was sieved, and the fraction of $0.5-1 \mathrm{~mm}$ was collected. In the following text, name of the material will be abbreviated as the DRB (Dandelion Root Biomaterial). 
Carrier-free radionuclides of $\mathrm{Sr}-85$ and Am-241 were supplied from the POLATOM Świerk (Poland) as certificated standard solutions. Aqueous solutions of the desired radionuclide concentrations were prepared by gravimetric dilution of the radionuclide standards with the hydrochloric acid ( $\mathrm{pH}$ 3) prior to checking their purity by gamma spectrometry.

Inulin (pharmaceutical material, Bio-Planet, Leszno, Poland) and all other chemicals (Sigma Aldrich/Fluka, Poland) were used without further purification.

\section{Adsorption experiments}

Batch adsorption experiments of $\mathrm{Sr}(\mathrm{II})$ and $\mathrm{Am}(\mathrm{III})$ ions by the DRB were carried out in polypropylene tubes. The initial strontium addition was either $100 \mathrm{mg} / \mathrm{L}$ (ca. $1.14 \mathrm{mmol} / \mathrm{L}$ ), added as $\mathrm{SrCl}_{2}$, or alternatively in the nca of ${ }^{85} \mathrm{Sr}$ (II) concentration. ${ }^{1}$ For the sorption studies of Am(III) in the presence of the weight amount of the salt, $100 \mathrm{mg} / \mathrm{L}$ (ca. $0.658 \mathrm{mmol} / \mathrm{L}$ ) of $\mathrm{EuCl}_{3}$ was applied. It is well known that $\mathrm{Eu}(\mathrm{III})$ is the $\mathrm{Am}$ (III) congener and that their chemistry is similar.

In all experiments, except those concerning studies of the dependence of sorption on the mass of the sorbent, the ratio of the DRB to liquid phase was $50 \mathrm{~g}$ to $1 \mathrm{~L}$ of the solution. Both phases were shaken together in the thermostatic shaker (type MKR 13; Merazet, Poznan, Poland) at room temperature. If not mentioned, the equilibration period was $3 \mathrm{~h}$ and the equilibrium $\mathrm{pH}$ was measured immediately prior to sampling. The liquid was separated from the solid by centrifuging (6000 rpm, $20 \mathrm{~min})$. Sr- 85 (half-life 64.84 days; major radiation: gamma$514.0 \mathrm{keV}$ ) and Am-241 (half-life 432.7 years; major radiation: alpha-5.4 MeV; gamma-59.5 keV) concentrations in the initial and equilibrium phases were determined radiometrically using a PerkinElmer 2480 Wizard $2^{\circledR}$ Automatic Gamma Counter equipped with the well-type $\mathrm{NaI}(\mathrm{Tl})$ detector. Calibration of the counter was done for both radionuclides using the gamma radiation calibrator commonly used in nuclear medicine laboratories. Throughout the work, metal concentrations were expressed in $\mathrm{kBqs}$ and were kept between $\sim 50$ and $\sim 425 \mathrm{kBq} \mathrm{mL}^{-1}$.

\footnotetext{
${ }^{1}$ No-carrier added (nca): a radioisotope quantity, which is essentially free of stable isotopes of the element in question, i.e. in the weight amount (de Goeij and Bonardi 2005).

2 The becquerel is the derived unit of radioactivity in the International System of Units (SI), symbolized as $\mathrm{Bq}$ and equal to one disintegration or nuclear transformation per second. Reduced to base SI units, $1 \mathrm{~Bq}=1 \mathrm{~s}^{-1}$. The becquerel is a small unit. In practical situations, radioactivity is often quantified in kilobecqerels $(\mathrm{kBq})$ or megabecquerels (MBq).
}

In each experiment, the sorption properties of the DRB were calculated as mean values from three independent samples, and all radiometric measurements of each sample were repeated three times. Standard deviations from these values were computed using the STDEV() function in Excel and presented in Figures as the error bars. In some cases, they are not visible, what means that in those cases, the SD values were smaller than the diameter of the points.

Sorption properties of the biomass were presented in terms of metal removal efficiency $\left(Y_{\mathrm{M}}\right)$, expressed in the percent:

$Y_{\mathrm{M}}=\frac{\left(C_{0}-C_{\mathrm{eq}}\right)}{C_{0}} \times 100 \%$

where $C_{0}$ and $C_{\mathrm{eq}}$ are the initial and equilibrium metal concentrations $\left(\mathrm{kBq} \mathrm{mL}^{-1}\right)$, respectively.

If necessary, apparent distribution coefficient between solid and aqueous phase $\left(K_{\mathrm{d}}, \mathrm{L} \mathrm{kg}^{-1}\right)$ was calculated using the following equation (Heuel-Fabianek 2014).

$K_{\mathrm{d}}=\frac{\left(C_{0}-C_{\mathrm{eq}}\right)}{C_{0}} \times \frac{V}{W}$

where the additional parameters are defined as $V$-the solution volume $(\mathrm{mL})$ and $W$ - the weight of DRB $(\mathrm{g})$.

Desorption of $\mathrm{Sr}(\mathrm{II})$ and Am(III) from the DRB sorbent was studied in four consecutive experiments. After the first $3 \mathrm{~h}$ of equilibration of phases (aqueous phase containing both radionuclides), suspensions containing the sorbent were centrifuged; the supernatant solution was replaced with the portion of pure water; and the phases were equilibrated for $3 \mathrm{~h}$. The process was repeated three times. In all experiments, the ratio of the DRB to liquid phase was from $50 \mathrm{~g}$ to $1 \mathrm{~L}$. The content of both metals in the solid phase and in the consecutive equilibrium solutions was determined radiometrically.

\section{Scanning electron microscopy (SEM)}

SEM studies of the dried samples were carried out at ambient temperature using a DSM 942 Scanning Electron Microscope (Zeiss-Leo, Germany) installed in the Institute of Nuclear Chemistry and Technology. The samples were covered with a thin gold layer. The fractures and surfaces of the samples were examined with magnifications of 100 , 1000 , and 5000. The images taken at a magnification of 100 or 5000 were selected for visualization of the most typical areas in the case of the samples.

\section{Fourier transform infrared spectroscopy}

The FT-IR spectra of the dried materials in $\mathrm{KBr}$ pellets (98 $\mathrm{mg} \mathrm{KBr}+2 \mathrm{mg}$ sample) were recorded in the $4000-400 \mathrm{~cm}^{-1}$ region with resolution of $1 \mathrm{~cm}^{-1}$ using the 
JASCO FT/IR-6200 type A instrument. Output data in the ASCII numeric form were processed with the OPUS software version 3.1 (Brucker) with aim to pick the peaks and visualized using the Origin 6.0 program (OriginLab Corporation, USA).

\section{Thermogravimetric studies}

Thermal analysis was carried out on a STA 449 Jupiter F1 simultaneous TGA-DSC system (Netzsch, Germany) operating in Maria Curie-Skłodowska University. The following operational conditions were used: temperature range-30-950 ${ }^{\circ} \mathrm{C}$, heating rate $-10{ }^{\circ} \mathrm{C} \min ^{-1}$, dynamic atmosphere of the synthetic air flow- $50 \mathrm{~mL} \mathrm{~min}^{-1}$, and sample mass $\approx 12 \mathrm{mg}$. As a reference, empty $\mathrm{Al}_{2} \mathrm{O}_{3}$ crucible was used.

Identification of the gas emitted during the decomposition process was performed using a QMS 403C Mass Spectrometer (Aëolos, Germany) coupled online to the STA 449 instrument. The mass spectrometer operated with an electron impact ionizer with energy $70 \mathrm{eV}$. The measurements were performed in scan mode for $m / z$, where $m$ is the mass of the molecule and $z$ is a charge of the molecule in electron charge units. All spectra were recorded in the range from 10 to $150 \mathrm{amu}$.

\section{Results and discussion}

\section{Homogeneity of biomass}

Five $0.1 \mathrm{~g}$ lots were randomly taken from the container with the grained DRB. Each sample of the biomaterial was equilibrated with the same volume of the initial solution containing both studied radionuclides under optimized conditions of $\mathrm{pH}$, temperature, and contact time. Values of the metal removal efficiency $\left(Y_{\mathrm{M}}\right)$ by the DRB for all samples did not differ from each other. Namely, they were: $83.16 \% \pm 0.59,83.24 \pm 0.31,83.25 \pm 0.39,82.83 \pm$ 0.46 , and 83.14 \pm 0.78 , as well as $72.38 \pm 2.29,71.39 \pm$ $0.53,70.38 \pm 1.09,72.74 \pm 0.63$, and $70.80 \pm 1.01 \%$ for $\mathrm{Am}(\mathrm{III})$ and $\mathrm{Sr}(\mathrm{II})$, respectively. These results show that biomaterial is homogeneous and that the biomass may be used for the entire study.

\section{Scanning electron microscopy (SEM)}

Characterization of the biosorbents by SEM offers topographical information of the solids with a virtually large depth of field, allowing different specimen parts to stay in focus at one time. SEM also has high resolution, making higher magnification possible for closely spaced materials.
However, this technique also has limitations, the most important being the lowest detectable particle size.

To study changes in the topology of the DRB surface occurring upon metal sorption, the surface of the initial biosorbent was compared with those loaded with water or europium metal, which is the congener of americium in the periodic chart. Respective pictures are presented in Fig. 1. It may be noticed that transformation of the surface morphology caused by the exposure of the sorbent to water and subsequently to metal ions is evident: The structure of the sorbent becomes more compact and aggregated. Inclusion of water into the sorbent structure causes swelling of the sorbent structure, while consecutive crosslinking it by metal ions results in further increase in the aggregates' dimensions. Similar observations have already been

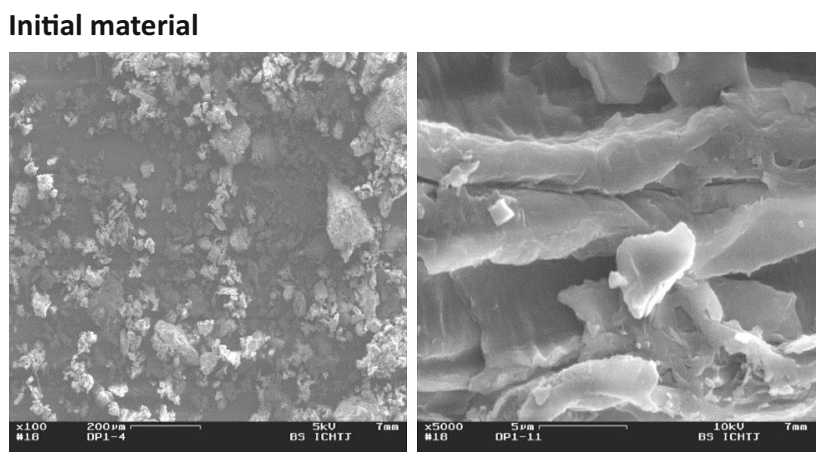

Water sorbed

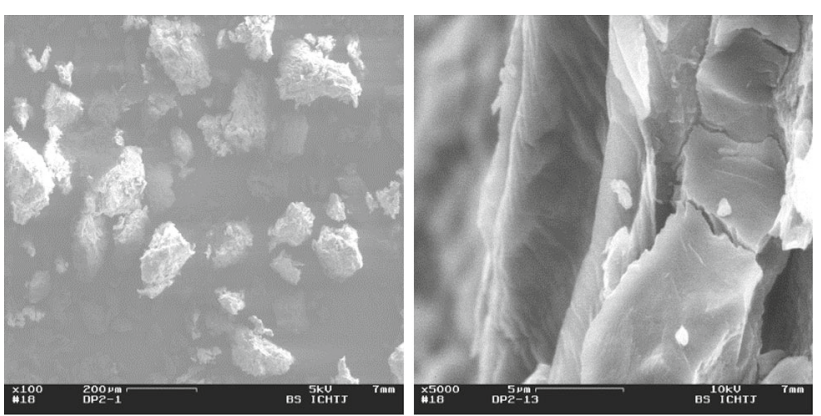

\section{Europium sorbed}
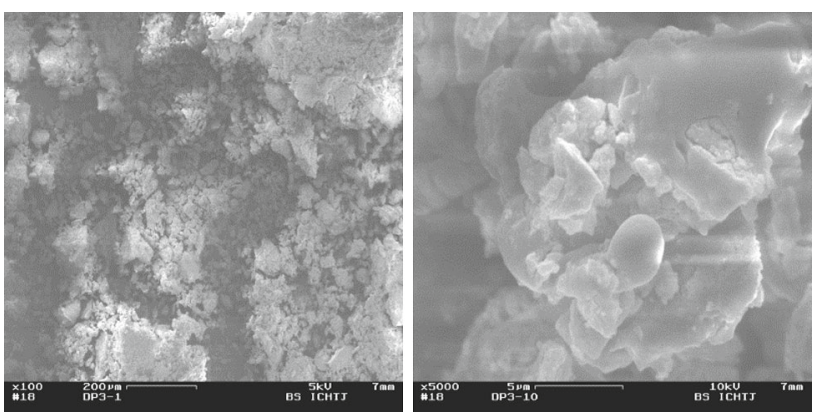

Fig. 1 Results of SEM observation of the dandelion root biosorbent. Magnification: $\times 100($ left $)$ and $\times 5000($ right $)$ 
reported, e.g., by Raize et al. (2004), for the macroalgae biomass.

\section{Fourier transform infrared spectroscopy (FT-IR)}

Hydroxyl groups in the inulin molecule were expected to be dominating metal complexing groups as compared with the ring oxygen atoms, so the adsorption properties of the DRB may be related to these sites. Analysis of the vibrational spectra (FT-IR) helps in the identification of chemical groups involved in the sorption of metal ions.

The FT-IR spectra of inulin, DRB, and strontium-loaded DRB are shown in Fig. 2. Both in the full spectral range (left part of the Figure) and in the fingerprint region $1800-600 \mathrm{~cm}^{-1}$ (Fig. 2, right), it can be seen their similarity. It may suggest that properties of inulin dominate these of other components of the DRB.

Because there is a total lack of the assignment for spectra of inulin, specification of the fingerprint peaks was made with the help of the published data for sucrose, i.e., the simple disaccharide composed of glucose and fructose linked via their anomeric carbons (Max 2007; Adina 2010), glucose, and fructose (Ibrahim 2006). The authors have shown that vibrations within the carbohydrate molecules show characteristic frequencies in the spectral region from 600 to $1500 \mathrm{~cm}^{-1}$ in which $\mathrm{C}-\mathrm{O}$ and $\mathrm{C}-\mathrm{C}$ group vibration modes are present. Also, the combination band of $\mathrm{O}-\mathrm{C}-\mathrm{H}$ and $\mathrm{C}-\mathrm{O}-\mathrm{H}$ deformation is located in the range from 1550 to $1300 \mathrm{~cm}^{-1}$. Finally, the in-plane deformation of the $\mathrm{C}-\mathrm{H}$ and $\mathrm{O}-\mathrm{H}$ bonds may be observed from 1370 to
Fig. 2 FTIR spectra $\left(4000-400 \mathrm{~cm}^{-1}\right)$ of the samples (left) and their fingerprint region $\left(1900-850 \mathrm{~cm}^{-1}\right)($ right $)$

\section{DRB}

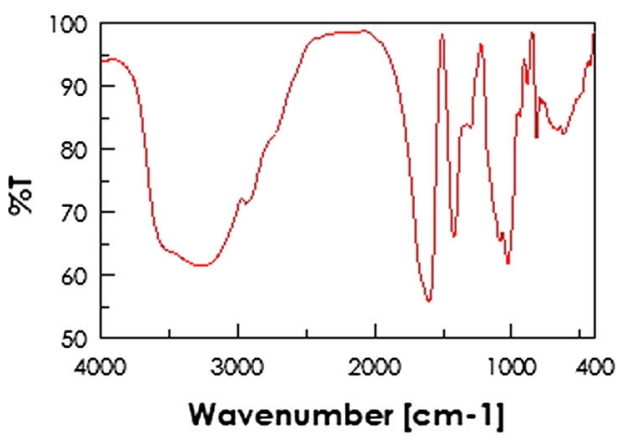

DRB (Sr-saturated)

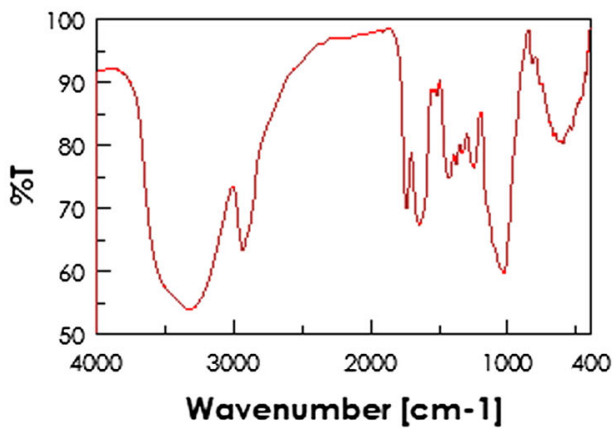

Inulin

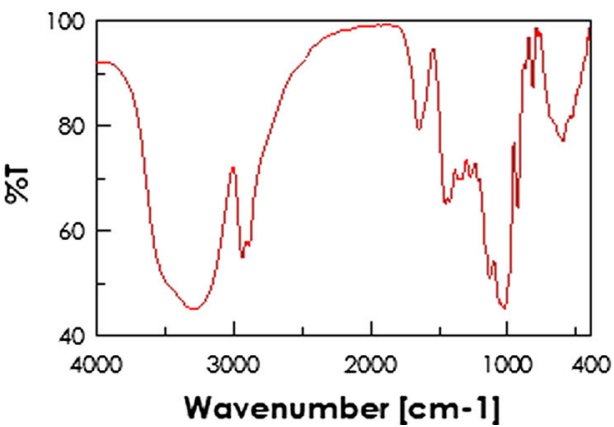

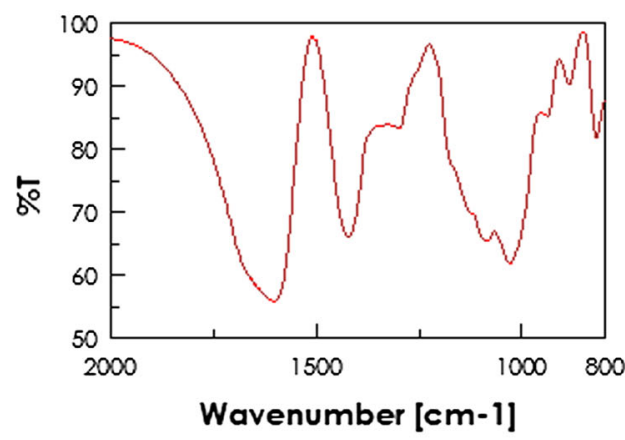
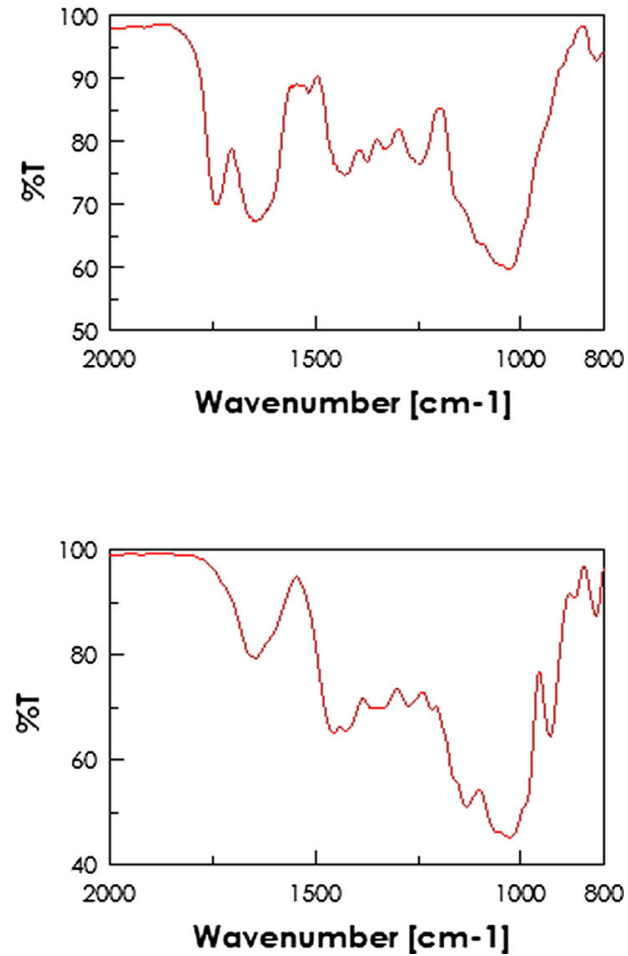
$1190 \mathrm{~cm}^{-1}$ while the $\mathrm{C}-\mathrm{O}$ and $\mathrm{C}-\mathrm{C}$ stretching from 1200 to $990 \mathrm{~cm}^{-1}$.

In the present work, main fingerprint vibrations ${ }^{3}$ of inulin have been placed at $1426 \mathrm{~cm}^{-1}(\delta \mathrm{C}-\mathrm{O}-\mathrm{H}+\delta \mathrm{O}-$ $\mathrm{C}-\mathrm{H})$ and $1345 \mathrm{~cm}^{-1}(\delta \mathrm{C}-\mathrm{O}-\mathrm{H})$. The endocyclic and exocyclic vibrations of the $\mathrm{C}-\mathrm{O}$ and $\mathrm{C}-\mathrm{C}$ bonds have been proposed for $1133 \mathrm{~cm}^{-1}$ ( $v \mathrm{C}-\mathrm{O}$ endo) and $1025 \mathrm{~cm}^{-1}(v$ $\mathrm{C}-\mathrm{O}$ exo). Corresponding vibrations for the DRB (row material) are located at $1423,1345,1116$, and $1034 \mathrm{~cm}^{-1}$, respectively. When the DRB was strontium-saturated, position of the first two bands are shifted toward the lower wavenumbers (namely to 1420 and $1341 \mathrm{~cm}^{-1}$, respectively). Because frequency of the vibration is inversely proportional to mass of vibrating entity, if mass of that object increases, peak shift is toward lower wave number side. Obviously, mass of strontium is greater of this of hydrogen in the hydroxyl groups.

The $\mathrm{Sr}-\mathrm{O}$ stretching vibration of the complex would occur at a lower frequency $\left(400-200 \mathrm{~cm}^{-1}\right)(\mathrm{Su} 2003)$ than those studied here.

Detailed description of the vibrational spectra will be published elsewhere.

\section{Sorption of the radionuclides: effect of contact time, pH, strontium concentration, and ionic strength}

In the following text, the concentrations expressed in SI units may be related to the radiation activity of the sample via the specific activity units. Since the aforementioned units refer to the radioactivity per mass unit of a radioactive compound in which one nucleus decays per one second, $\mathrm{s}^{-1}$, the number of $\mathrm{MBq} / \mathrm{mg}$ may be applied to express the above-mentioned concentrations.

The specific activity of a carrier-free radionuclide sample is related to the half-life of the radionuclide: the shorter the half-life, the higher the specific activity. Specific activity values important in this study are: $8.7540 \times 10^{4} \mathrm{MBq} \mathrm{mg}^{-1} \quad(\mathrm{Sr}-85) \quad$ and 12.672 $\mathrm{MBq} \times \mathrm{mg}^{-1}(\mathrm{Am}-241)$.

\section{Kinetics of sorption}

The adsorption equilibrium time between the adsorbates and the sorbent is important for designing batch biosorption experiments. Therefore, adsorption of $\mathrm{Sr}(\mathrm{II})$ on the DRB was studied as a function of contact time (Fig. 3). It is evident from the figure that adsorption equilibrium was established within $90 \mathrm{~min}$, and the optimum contact time

\footnotetext{
3 Abbreviations: fru, D-fructosyl moiety; $v$, stretch; $\delta$, deformation; $\omega$, wag; endo, endocyclic; exo, exocyclic; sh, shoulder; Exocyclic, external to a chemical ring structure; endocyclic, within a cycle or ring, for example, the six carbon atoms of the ring.
}

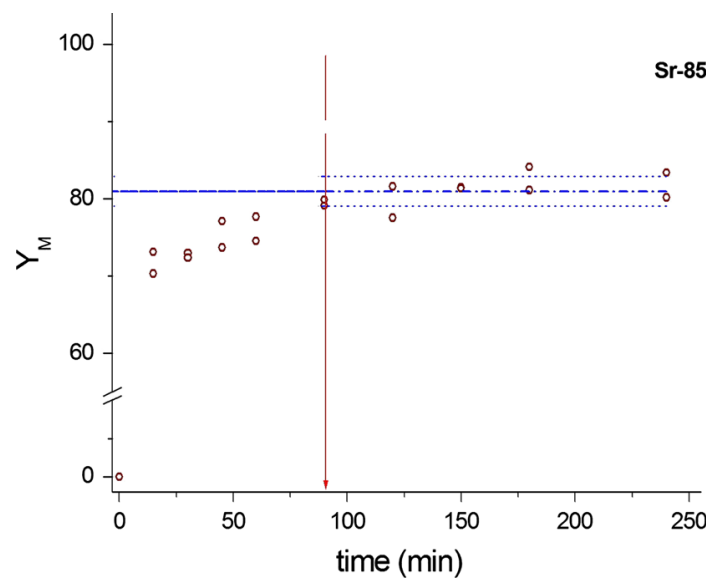

Fig. 3 Time depending removal efficiency of strontium(II) by the dandelion root biomass $\left(25^{\circ} \mathrm{C}\right.$, initial $\left.\mathrm{pH} 5.6\right)$

was selected as $180 \mathrm{~min}$ for further experiments. As seen in the figure, the adsorption rate is very fast within $30 \mathrm{~min}$, and thereafter, it becomes slower within the range of 30-90 min. Finally, the adsorption capacity does not vary significantly after $180 \mathrm{~min}$, and the adsorption would be in a state of dynamic equilibrium between the $\mathrm{Sr}(\mathrm{II})$ desorption and adsorption. In sum, at $\mathrm{pH}$ ca. 5.6 and a temperature of $25{ }^{\circ} \mathrm{C}$, adsorption equilibrium reaches a value of $81 \pm 2 \%$.

In order to examine a wastewater treatment process, it is important to predict the rate of biosorption operation. In this study, two kinetic models were used to fit the experimental data to the Lagergren pseudo-first-order and the Blanchard pseudo-second-order models. Respective equations may be found, for example, in Liu and Liu (2008).

The applicability of both kinetic simulations was determined by checking the linear determination coefficients $\left(R^{2}\right)$ of the linear forms of equations and nearness of values between experimental and calculated sorption capacity values. It was found that the pseudo-second-order model provides better fit for $\mathrm{Sr}$ (II) removal from aqueous solutions by the DRB. The values of $K_{2}$ (i.e., the pseudosecond-order rate constant $\left(\mathrm{kBq}^{-1} \min ^{-1}\right)$ and $R^{2}$ are $1.33 \times 10^{5}$ and 0.9986 , respectively.

In separate experiments, it has been found that the sorption capacity of strontium and europium metals by the DRB is 63.69 and $80.64 \mathrm{mg} / \mathrm{g}$, respectively (ICP-MS determinations). This means that these amounts of the salts saturate all sorption centers on the sorbent surface.

\section{Effect of the acidity of the aqueous solution}

The initial acidity of the solution is one of the decisive factors determining the efficiency of metal uptake from aqueous solutions. It affects both surface of the sorbent as 
well as the speciation of the metal ion in solution which additionally depends on the concentration of the metal.

The results obtained for strontium(II) and americium(III) sorption for the initial $\mathrm{pH}$ ranging from 2 to 10 are shown in Fig. 4. Total $\mathrm{Sr}$ and Am concentration was $10^{-6} \mathrm{~mol} \mathrm{~L}^{-1}$ and $3.2 \times 10^{-9} \mathrm{~mol} \mathrm{~L}^{-1}$, respectively. It can be seen that the uptake of both metals by the DRB in the $\mathrm{pH}$ range from 3 to 10 oscillates slightly around the values at $91.4 \pm 1.3 \%$ for $\mathrm{Am}(\mathrm{III})$ and at $76.0 \pm 1.0 \%$ for $\mathrm{Sr}(\mathrm{II})$.

The calculations by Hydra-Medusa software (Oszczak and Fuks 2015) show in acidic conditions, the only present species are $\mathrm{Sr}$ (II) and/or $\mathrm{Am}(\mathrm{III})$. However, at $\mathrm{pH}$ 6.5-7, because of the carbon dioxide present in the atmosphere monovalent $\mathrm{Sr}\left(\mathrm{HCO}_{3}\right)^{+}, \quad \mathrm{Am}\left(\mathrm{CO}_{3}\right)^{+}$and divalent $\mathrm{Am}(\mathrm{OH})^{2+}$ species may be found in significant amounts. Moreover, the main constituent of the DRB is inulin. It is the carbohydrate with a number of alcoholic and etheric groups. The ionization state of these groups is highly dependent on $\mathrm{pH}$ and until now not recognized reliably. Generally, at $\mathrm{pH} \sim 1.5$, the majority of these groups are protonated, inducing positive or neutral charge, and hence, their interactions with positively charged strontium and americium species are not favoured by electrostatic forces. With increasing $\mathrm{pH}$, the negative charge density on the functional groups increases which favors their interaction with the positively charged $\mathrm{Sr}$ (II) and Am(III) species, thus their biosorption increases. As a result, the interplay of both above-mentioned factors is reflected in the complicated, irregular curves presenting the effects of the acidity on the sorption.

\section{Effect of the nca metal concentration}

Graphical representations showing a relationship between the amount of the adsorbed species by a unit weight of adsorbent and the amount of the adsorbate remaining in the solution at equilibrium conditions are named the adsorption isotherms. So far, a great number of such functional models have been proposed. Many of the most popular biosorption isotherms have been recently presented and discussed by Liu and Liu (2008). Parameters existing in the particular isotherms' equations offer different information about the sorption mechanism, surface properties, and the binding sites of the sorbent.

Both of the most popular models, namely the Langmuir and the Freundlich isotherms, were used to analyze the adsorption data in the presented studies. Experiments were carried out in the batch mode experiments, and each sample contained different volumes of the initial standard solution containing both radionuclides studied. Sorption isotherms were obtained in the range of initial concentration of the radionuclides from $\sim 50$ up to $\sim 450 \mathrm{kBq} / \mathrm{mL}$. It was observed that the amount of both metals sorbed on the DRB increased with their initial concentrations, and the plateau was not reached at this range of concentrations.

Figure 5 shows the adsorption isotherms of Am(III) and $\mathrm{Sr}$ (II) for the DRB at room temperature. The parameters and constants appearing in both equations were estimated through linear regression by plotting $C_{\mathrm{eq}} / q_{\mathrm{eq}}$ versus $C_{\mathrm{eq}}$ in the former case and $\log q_{\mathrm{eq}}$ versus $\log C_{\mathrm{eq}}$ in the latter. It was found that the experimental data fit the Freundlich equation better than the Langmuir one. In detail, coefficients of determination $\left(R^{2}\right)$ for the Freundlich model are 0.93 and 0.96 for $\mathrm{Sr}$ (II) and $\mathrm{Am}(\mathrm{III})$, respectively. On the contrary, corresponding $R^{2}$ values for the Langmuir isotherms are slightly higher than 0.65 .

The Freundlich equation provides us with the values of $\log \left(K_{\mathrm{f}}\right)$, which may be assumed as a measure of adsorption capacity, being $2.787 \pm 0.086$ and $3.155 \pm 0.071$ for $\mathrm{Sr}(\mathrm{II})$ and $\mathrm{Am}(\mathrm{III})$, respectively. Corresponding $\mathrm{n}_{\mathrm{f}}$ values, usually attributed to the adsorption intensity, are $1.171 \pm 0.046$ and $1.284 \pm 0.040$, respectively.

Langmuir and Freundlich isotherms are often accounted to be insufficient for explaining the physical and chemical characteristics of adsorption. The Dubinin-Radushkevich (D-R) isotherm, apart from being an analogue of the Langmuir isotherm, is more general than the latter, as it is not based on ideal assumptions such as equipotential of sorption sites, absence of steric hindrance between sorbed and incoming particles, and surface homogeneity on the microscopic level. The D-R model is commonly used to describe the sorption process of single-solute systems with a Gaussian energy distribution onto a heterogeneous surface (Liu and Liu 2008).

The linear form of the D-R equation may be presented as:

$\ln \left(q_{\mathrm{eq}}\right)=\ln \left(q_{\mathrm{m}}\right)-K_{D-R} \times \varepsilon^{2}$

where $q_{\mathrm{m}}$ denotes maximum adsorption capacity $\left(\mathrm{kBq} \mathrm{g}^{-1}\right), K_{D-R}\left(\mathrm{~mol}^{2} \mathrm{~kJ}^{2}\right)$ is a constant related to the mean adsorption energy, and $\varepsilon$ is the Polanyi potential. Equation (3) allows computation of the mean free energy $E$ of sorption per molecule of the sorbate transferred to the surface of the solid from infinity in the solution (Miró et al. 2008). This computation may be done after relation (4):

$E=\frac{1}{\sqrt{2 \times K_{D-R}}}$

The $R^{2}$ values of fitting the lines (3) being about 0.97 exceed slightly these for the Freundlich equation. Slopes of the lines in the D-R isotherm plots provide the free energy values of sorption $4.09 \pm 1.74$ and $6.52 \pm 2.82 \mathrm{~kJ} / \mathrm{mol}$ for 


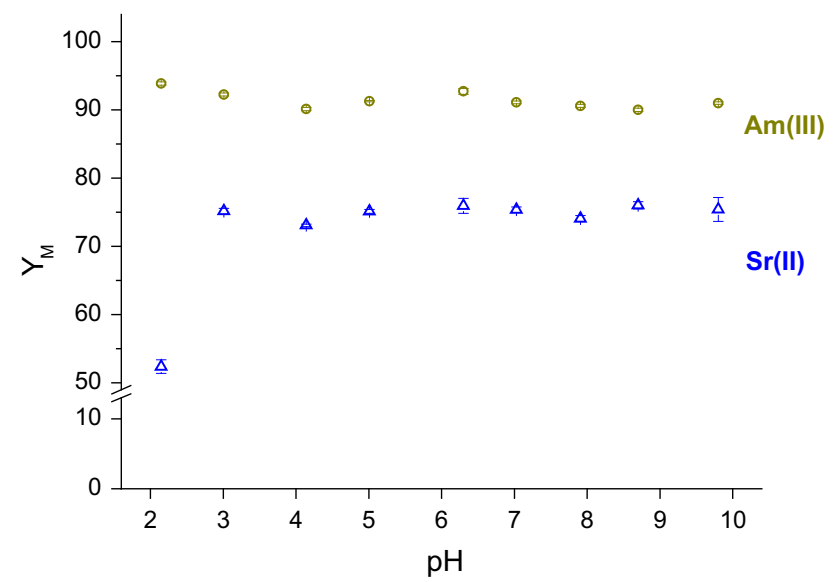

Fig. 4 Effect of acidity on the removal efficiency of both cations by the dandelion root biomass $\left(25^{\circ} \mathrm{C}, t=2 \mathrm{~h}\right.$. $)$

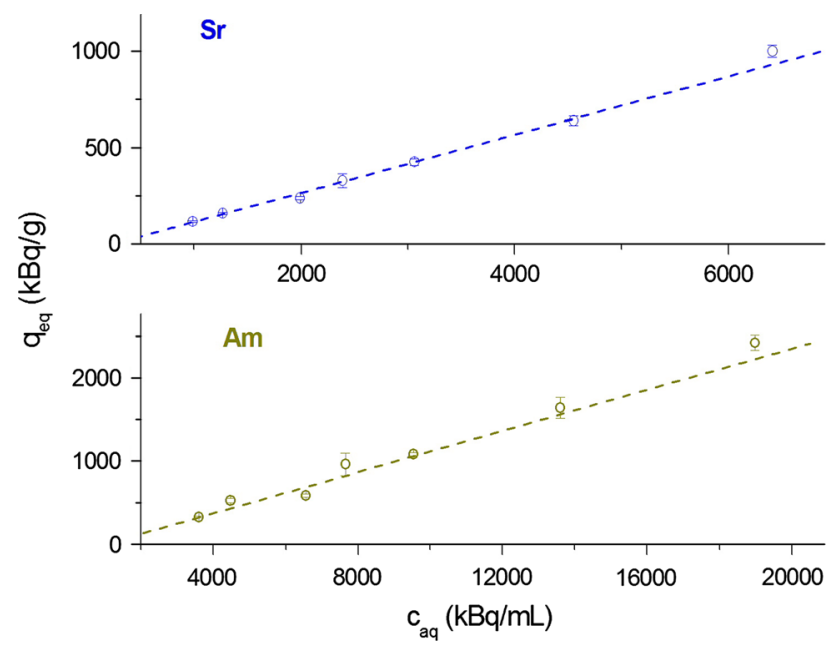

Fig. 5 Effect of the ion concentration on the uptake of $\mathrm{Sr}(\mathrm{II})$ (a) and $\mathrm{Am}$ (III) (b) by the dandelion root biomass $\left(25^{\circ} \mathrm{C}, t=2 \mathrm{~h}\right.$.)

$\mathrm{Sr}(\mathrm{II})$ and $\mathrm{Am}(\mathrm{III})$, respectively. Values of $\ln \left(q_{\mathrm{m}}\right)$ $4.29 \pm 0.05$ and $2.38 \pm 0.09$ for the aforementioned sorbates indicate a greater saturation capacity of the sorbent surface by $\mathrm{Sr}(\mathrm{II})$ than Am(III). Values of sorption energy are less than $8 \mathrm{~kJ} \mathrm{~mol}^{-1}$. Thus, it may be suggested that physical adsorption is the process involved in the adsorption of both metal ions (Jain et al. 2009). On the contrary, values of sorption energy in the range of $8-16 \mathrm{~kJ} \mathrm{~mol}^{-1}$ reflect the ion exchange mechanism (Hasany and Chaudhary 1996).

The Freundlich and D-R isotherms are presented in Fig. 6.

\section{Effect of the mass of sorbent}

The dependence of $\mathrm{Sr}$ (II) and Am(III) sorption on the ratio of the adsorbent mass:decontaminated solution volume was studied by varying the amount of the sorbent from 2.5 to
$50 \mathrm{mg} / \mathrm{mL}$, keeping other parameters ( $\mathrm{pH}$ and contact time) constant. Figure 7 shows the results obtained. It can be seen, as expected, that the sorption capacity improved with increasing sorbent dose in the full range up to $30 \mathrm{mg} / \mathrm{mL}$. About $90 \%$ of $\mathrm{Am}(\mathrm{III})$ and $80 \%$ of $\mathrm{Sr}(\mathrm{II})$ were removed when $30 \mathrm{mg}$ of the sorbent was put in $1 \mathrm{~mL}$ of the solution. After reaching this dose, the sorption percent values did not change considerably, even with further addition of the sorbent.

The aforementioned results have been compared with those obtained for the solutions containing $0.1 \mathrm{M}$ of the chlorides formed by the stabile isotopes doped with the appropriate radionuclides. In the case of the Am(III) solutions, we used its congener, europium (i.e., salt of the element placed in the periodic table above americium). The results are shown in Fig. 6. It is evident that co-sorption of the gravimetric amount of the non-radioactive salt influences sorption of both radionuclides in an important way. As an example, for concentration $30 \mathrm{mg} / \mathrm{mL}$ of the DRB, the observed decrease is of range of $25 \%$ points.

\section{Effects of the chelating agents (citric acid, oxalic acid, and EDTA mixture) on sorption of the radionuclides-decontamination of the polluted liquids}

Treatment of liquid radioactive wastes quite often requires the use of special decontamination solutions. Among the most popular are CANDEREM (CANadian DEcontamination and REMediation process) and CANDECON (CANadian DECONtamination process). The approximate composition of the solutions is $0.3 \mathrm{~g}^{-1}$ oxalic acid, $0.2 \mathrm{~g} \mathrm{l}^{-1}$ citric acid, and $0.5 \mathrm{~g} \mathrm{l}^{-1}$ EDTA (i.e., about $2 \times 10^{-3} \mathrm{M}$ each) (Dulama et al. 2009). An alternative method, called the LOMI decontamination process, incorporates an initial injection of a diluted LOMI reductive solution (vanadous formate, picolinic acid, and sodium hydroxide) into a decontaminated circuit, followed by operation of a small cluster of cation exchange columns during the decontamination process (Wood et al. 1998). However, this is applicable mainly for the high-level radioactive waste (HLW), so it was not examined in the present studies.

To check the easily available DRB as a potential sorbent in the pretreatment and storage of the low-level waste (LLW) solutions, the material was tested by sorption of Sr(II) and Am(III) from the artificial CANDEREM decontamination liquid. Figure 8 shows the obtained results.

It was found that complexation of $\mathrm{Sr}$ (II) and $\mathrm{Am}$ (III) by the mixture of strong chelating agents, as the citrate, oxalate, and EDTA, does not significantly diminish the sorption efficiency of the sorbent. The percentage of sorption from the solutions of the initial $\mathrm{pH} 3,5$, or 9, respectively, 

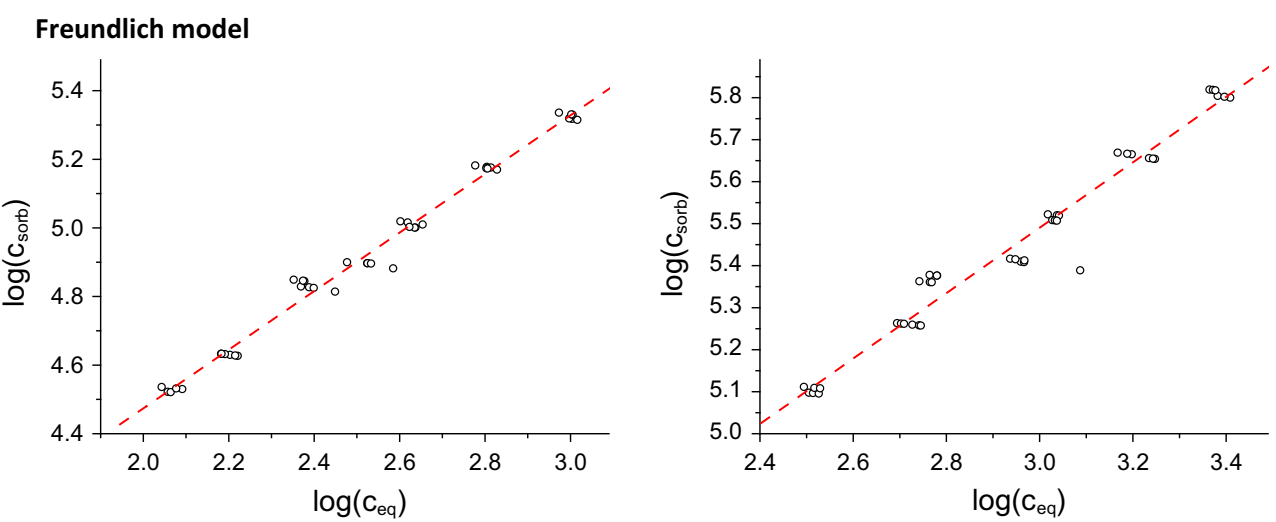

\section{D-R model}
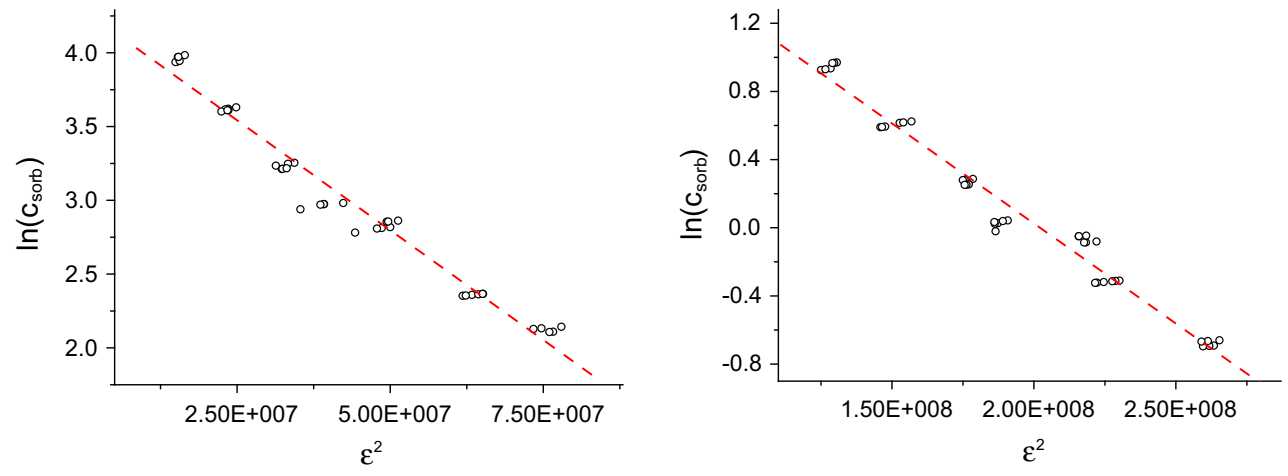

Fig. 6 Linear presentation of Freundlich and D-R sorption models for $\operatorname{Sr}(\mathrm{II})$ and Am(III) sorption onto DRB. Sr(II) metal ions-left, Am(III) metal ions-right

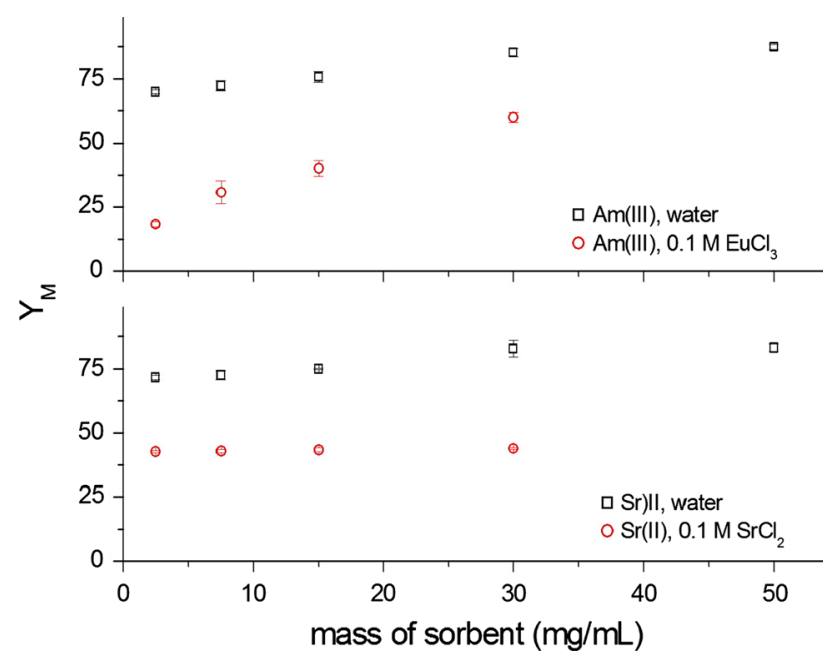

Fig. 7 Effect of mass of the DRB on the removal efficiency of both cations by the dandelion root biomass $\left(25^{\circ} \mathrm{C}, t=2 \mathrm{~h}\right.$.)

were in the range of 90 and $75 \%$ for $\mathrm{Am}(\mathrm{II})$ and $\mathrm{Sr}(\mathrm{II})$, respectively. This implies that the designing of the water processing should not include any additional steps.

\section{Desorption (recycling of the biosorbent)}

The recycling of the biomass was investigated in the consecutive desorption experiments. A sample of the biosorbent loaded with both radiometals was contacted with subsequent portions of fresh water until two consecutive experiments provided similar results. Such procedure ensured that all of the residual solution containing the radioactive matter was washed from the pores existing on the surface of the sorbent. The recovery ratio was calculated using the following equation:

Recoverey ratio $=\frac{\text { Amount of the radiometal desorbed }}{\text { Amount of the radiometal dsorbed }} \times 100 \%$

We found that four consecutive washings with water were enough to reach constant values of the recovery ratio. Its value appeared to be $0.331 \pm 0.004 \%$ and $0.821 \pm 0.020 \%$ for $\mathrm{Sr}(\mathrm{II})$ and $\mathrm{Am}(\mathrm{III})$, respectively. Such small values show that if fixed by the DRB, both radionuclides may be safely stored as solid phase matter in the radioactive waste repository. 
Fig. 8 Sorption of $\operatorname{Sr}(\mathrm{II})$ and Am(III) by DRB from drinking water (a, c, respectively) as compared with the decontamination solutions (b, $\mathbf{d}$, respectively)

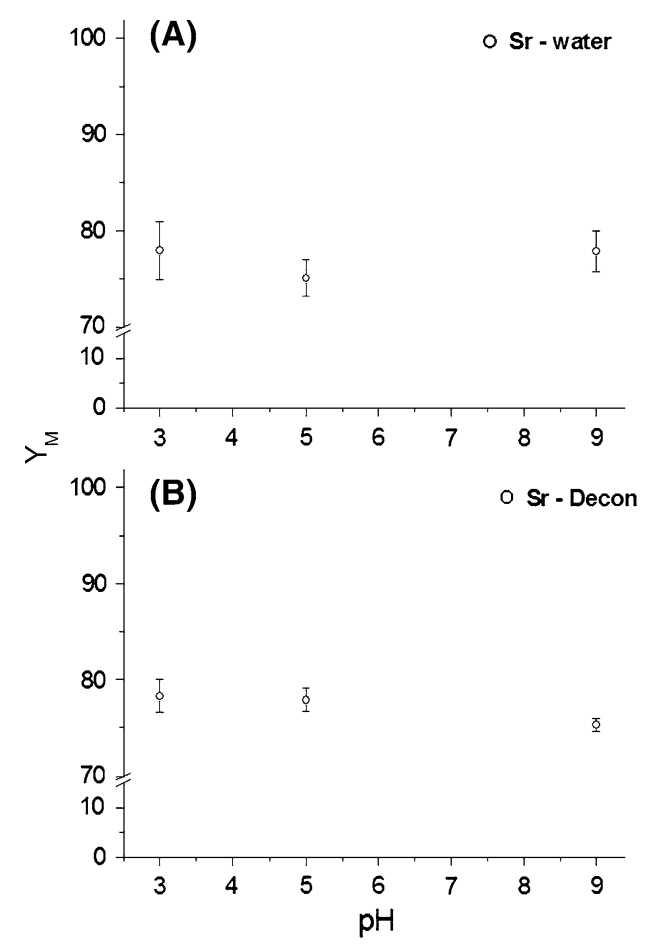

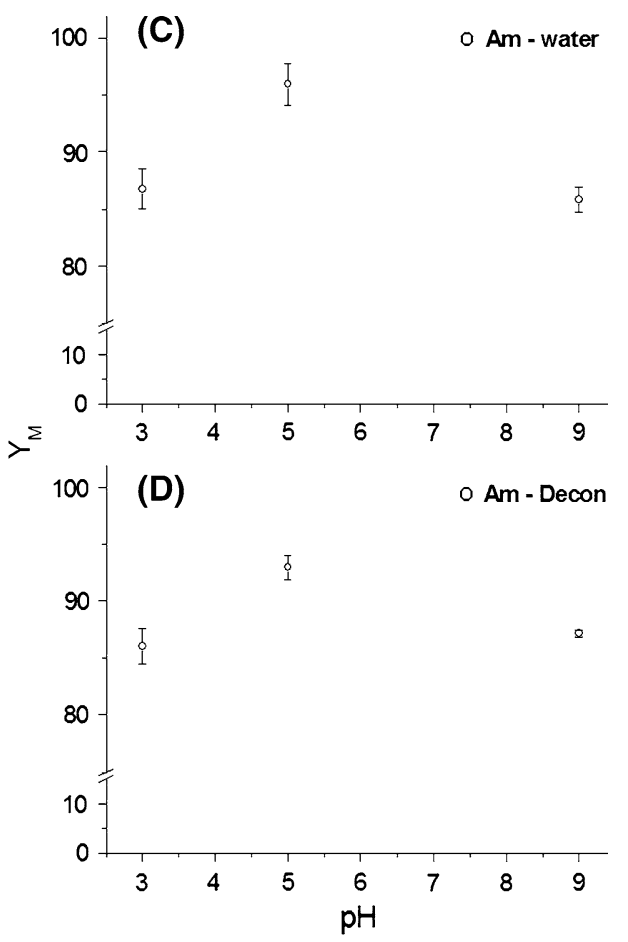

\section{Thermal studies of the DRB samples}

It is textbook knowledge that organic matter breaks down into small molecular components if heated and does not recombine on cooling. This process may be applied for the significant reduction of the volume/mass of the industrial wastes containing metals, which is of special importance for their storage. Carbon dioxide, carbon monoxide, and water, with small quantities of acids, aldehydes, and volatile solids, are found as main thermal decomposition products of the carbohydrates (Puddington 1948).

For this purpose, thermogravimetric analysis (TGA) and differential thermal analysis (DTA) have been undertaken in the temperature range of $20-950{ }^{\circ} \mathrm{C}$. Raw material, as well as the sorbent saturated with water and europium(III) chloride, has been studied. Mass decrease in the samples was detected using the $\mathrm{Al}_{2} \mathrm{O}_{3}$ thermobalance, and the main volatile decomposition products were observed by the MS method. Figure 9 and Table 1 present the main results obtained.

Analysis of the TGA, DTG, and MS curves shows that as a result of heating, the DRB main decomposition temperature ranges occur at temperatures of about 100, 220, 310 , and $450{ }^{\circ} \mathrm{C}$, respectively. Mass changes in the raw material as well as the sorbent saturated with water appear to be similar to each other and differ significantly from those recorded for the sorbent saturated with europium(III). For both former materials, two pronounced decomposition regions occur at the temperature ranges of about 220 and
$450{ }^{\circ} \mathrm{C}$, respectively. Mass loss of these samples has been found to be at least $30 \%$ at each mentioned temperature. The main volatile products found were water steam $\left(220^{\circ} \mathrm{C}\right)$ and carbon dioxide $\left(450{ }^{\circ} \mathrm{C}\right)$. Also, at the temperature of around $310{ }^{\circ} \mathrm{C}$, both materials lose about $25 \%$ of their initial mass with more or less equal amounts of the aforementioned compounds. When saturated with europium(III), DRB decomposes with smaller efficiency. Detected total mass loss decreases to about $50 \%$. However, detected gaseous products of the degradation remain the same. Simultaneously, all decomposition temperatures increase about $20^{\circ} \mathrm{C}$, and the first stage of water release appears to be more intensive. The aforementioned decrease in the mass loss may be associated with the formation of the non-volatile europium(III) species.

\section{Dandelion root biosorbent (DRB) compared with other natural sorbents}

Sorption technology, utilizing natural materials (inorganic and organic, as well) or agricultural wastes, is highly efficient for the removal of metal ions from aqueous media. It offers an effective but cheaper alternative compared to traditional chemical and physical remediation and decontamination techniques. Search in the International Atomic Energy Agency (IAEA) literature INIS database for the radioactive metal sorption from aqueous solutions has revealed existence of about 15.500 publications (INIS Web site). In particular, about 5.500 from them have been found 

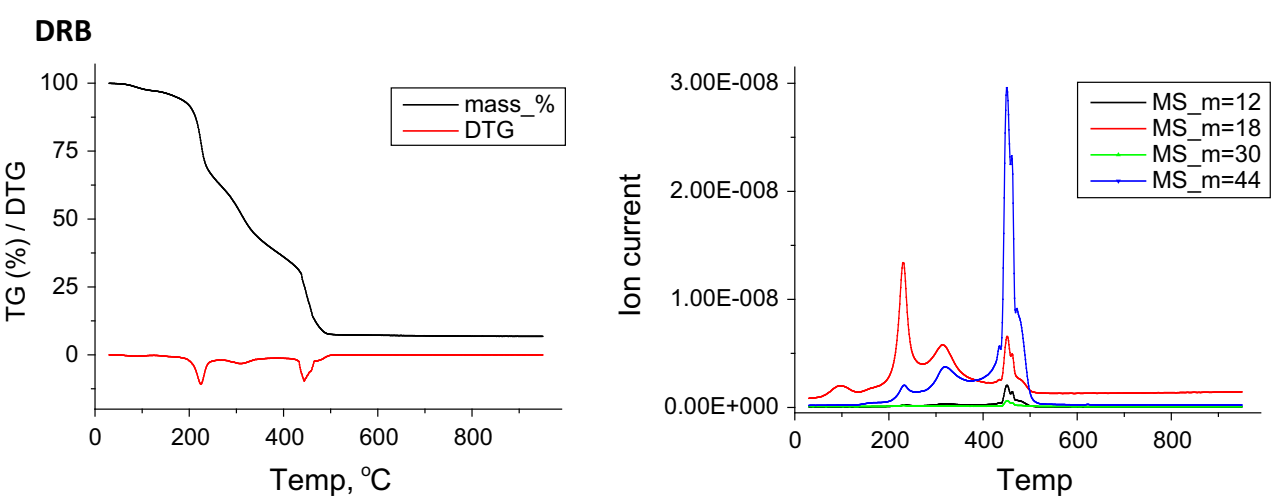

\section{DRB - water}
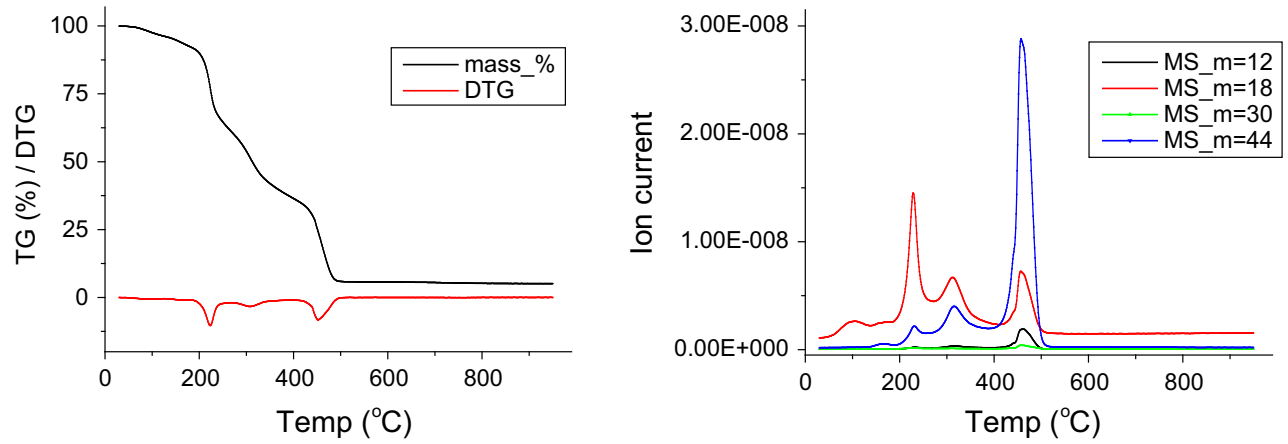

\section{DRB - europium nitrate}
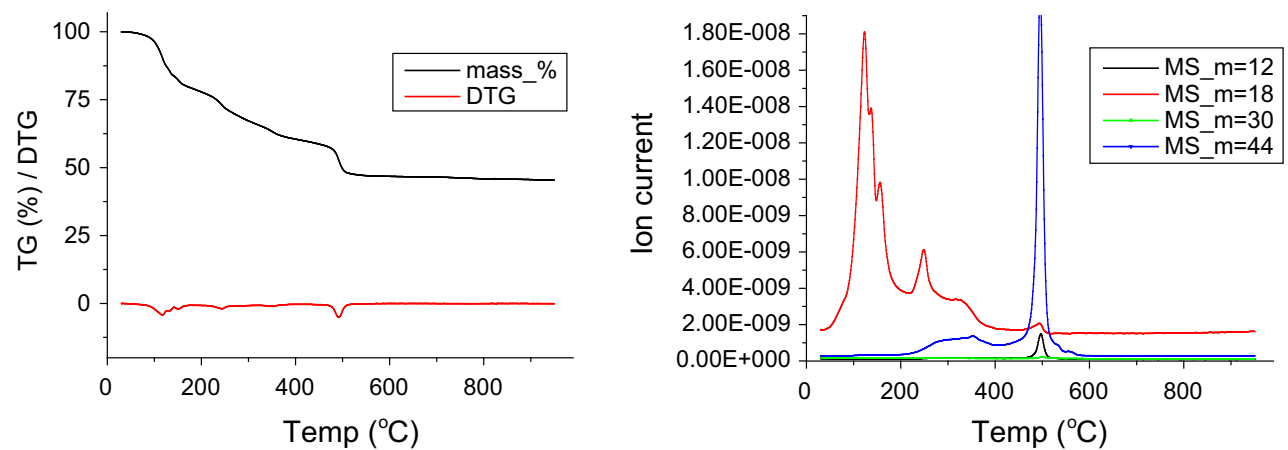

Fig. 9 Thermal analysis of the DRB samples: raw material, sorbent saturated with water and with the europium(III) nitrate (left), and the mass spectra of the main volatile decomposition products (right)

Table 1 Thermal

decomposition of the samples studied

\begin{tabular}{|c|c|c|c|c|c|c|}
\hline \multicolumn{2}{|l|}{ DRB } & \multicolumn{2}{|c|}{ DRB-water } & \multicolumn{2}{|c|}{ DRB-europium } & \multirow{2}{*}{ Main volatile products } \\
\hline$T\left({ }^{\circ} \mathrm{C}\right)$ & $\Delta m(\%)$ & $T\left({ }^{\circ} \mathrm{C}\right)$ & $\Delta m(\%)$ & $T\left({ }^{\circ} \mathrm{C}\right)$ & $\Delta m(\%)$ & \\
\hline 89.4 & 2.8 & 89.7 & 7.6 & $\begin{array}{l}117.2 \\
132.1 \\
151.5\end{array}$ & $\begin{array}{l}16.21 \\
4.13\end{array}$ & $\begin{array}{l}\mathrm{H}_{2} \mathrm{O} \\
\mathrm{H}_{2} \mathrm{O}\end{array}$ \\
\hline 224.5 & 33.2 & 223.1 & 30.26 & 243.0 & 13.95 & $\mathrm{H}_{2} \mathrm{O}$ \\
\hline 309 & 25.1 & 306.6 & 24.88 & 349.6 & 5.02 & $\mathrm{CO}_{2}, \mathrm{H}_{2} \mathrm{O}$ \\
\hline 442.2 & 32.2 & 452.1 & 32.05 & 491.9 & 15.28 & $\mathrm{CO}_{2}, \mathrm{C}$ \\
\hline Total mass loss & 94 & & 95 & & 54 & \\
\hline
\end{tabular}


Table 2 Selected sorbents for strontium(II) and americium(III); literature data

\begin{tabular}{|c|c|c|c|c|}
\hline \multirow[t]{2}{*}{ Sorbent } & \multicolumn{2}{|l|}{$\operatorname{Sr}(\mathrm{II})$} & \multicolumn{2}{|l|}{ Am(III) } \\
\hline & $\log K_{\mathrm{d}}$ & Literature & $\log K_{\mathrm{d}}$ & Literature \\
\hline Zeolites & 2.6 & Orth and Kurath (1994) & 4.4 & (Gładysz-Płaska et al. 2016) \\
\hline Clays & $\sim 2.9$ & Miró et al. (2008) & $2.5-6$ & Miró et al. (2008) \\
\hline Polyantimonic Acid & 2.0 & Orth and Kurath (1994) & 4.7 & (Hideaki 96-047) \\
\hline Hydroxyapatite & 3.3 & Rosskopfová et al. (2011) & 5.5 & Krejzler and Narbutt (2003) \\
\hline Hematite & & & 4.4 & (Dien DE-AC09-08SR22470) \\
\hline Algae/alginate & 2.0 & Grabias et al. (2015) & 4.2 & Oszczak et al. (2015) \\
\hline Chitosan & 0.6 & Fuks et al. (2015) & 3.6 & Kosyakov et al. (2000) \\
\hline Coconut fibers (Cocosnucifera L.) & & & 1.6 & Fonseca et al. (2013) \\
\hline Granular activated carbon & 1.6 & Caccin et al. (2013) & 3.4 & Miró et al. (2008) \\
\hline Fungi & & & 2.6 & Liu et al. (2002) \\
\hline Pecan (orzechy) shells activated with $\mathrm{H}_{3} \mathrm{PO}_{4}$ & 2.2 & Caccin et al. (2013) & & \\
\hline Coconut shell activated carbon (Norit) & 0.3 & Caccin et al. (2013) & & \\
\hline Coffee husks & & & 1.4 & Ferreira et al. (2011) \\
\hline DRB & 2.2 & This study & 2.3 & This study \\
\hline
\end{tabular}

for the americium and more than 9.000 for strontium. Selected data are presented in Table 2. If necessary, some of the data have been recalculated according to Eq. 2 .

Inorganic ion exchangers such as aluminosilicates (e.g., zeolites), clays, hydrous iron oxides, hydrous titanium oxide, hydrous zirconium oxide, polyantimonic acid, and many others could be useful for treating contaminated ground- and surface water, soil leachates, and low-level aqueous wastes. The metal-loaded inorganic ion exchangers might be appropriate as a final waste form or more amenable to incorporation into other inorganic waste forms such as glass, ceramics, or grouts. The sorbents are more resistant to ionizing radiation, high temperatures, and harsh chemical environments than the more common organic polymeric materials.

In recent years, the need for the alternative safe and economical methods of the elimination of heavy/radioactive metals from contaminated waters has called for the intensive research. Low-cost agricultural waste by-products such as sugarcane bagasse, rice husk, sawdust, coconut husk, oil palm shell, neem bark, etc. for the elimination of heavy metals from wastewater have been investigated in addition to the species obtained from various plants or living organisms. In general, these sorbents can be termed as a lower-cost material, more ready for the recycling, and easier to store than the inorganic sorbents.

As it can be observed from Table 2, sorption properties of the proposed in present work material, even if do not comparable with the inorganic sorbents, correspond well to the most common natural organic sorbents.

\section{Conclusion}

Batch sorption experiments were carried out to study the effects of contact time, initial concentration of the metal, and $\mathrm{pH}$ of the media as well as of the sorbent amount on the adsorption of $\mathrm{Sr}$ (II)-85 and $\mathrm{Am}$ (III)-241 radiometals by the dandelion root biosorbent (DRB).

The equilibration time of about 90 min was found to be enough for adsorption of $\mathrm{Sr}(\mathrm{II})$. The maximum adsorption capacity of the DRB at a pH of about 6.0 was found to be 63.69 and $80.64 \mathrm{mg} \mathrm{g}^{-1}$ for $\mathrm{Sr}(\mathrm{II})$ and $\mathrm{Eu}(\mathrm{III})$, respectively. The last was used as the Am(III) congener on the periodic chart, so their chemistry is similar to each other. In general, Am(III) is present only in trace amounts.

Kinetic studies have shown that sorption best fits the pseudo-second-order model. The Freundlich model was found to best describe the sorption of both metals studied as compared to the Langmuir model. Further inspection of the sorption data based on the D-R model leads to the conclusion that the physical interactions are most important in the sorption of both elements studied.

Thermogravimetric studies have shown that the proposed sorbent after being used for immobilization of the radionuclides successfully may be processed thermally with aim to reduce mass of the waste.

Taking into account removal efficiency $\left(Y_{\mathrm{M}}\right)$ of the proposed sorbent, application of three consecutive sorption procedures with new portions of the DRB, the decontaminated aqueous solutions will be completely purified from the radiometals. 
Acknowledgments We thank Mrs. Wanda DALECKA for assistance in the experimental work and Dr. Bozena SARTOWSKA for the SEM investigations. Dr. Dariusz STERNIK is acknowledged for performing the thermogravimetric analyses. The studies have been performed as the statutory work of the Institute of Nuclear Chemistry and Technology (Warszawa) and the University of Maria Curie-Sklodowska (Lublin).

\section{References}

Adina C, Florinela F, Abdelmoumen T, Carmen S (2010) Application of FTIR spectroscopy for a rapid determination of some hydrolytic enzymes activity on sea buckthorn substrate. Rom Biotechn Letters 15:5738-5744

Bisset NG, Phillipson JD, Czygan FC, Frohne D, Höltzel D, Nagell A, Pfander HJ, Willuhn G, Buff W (eds) (1994) Herbal drugs and phytopharmaceuticals: a handbook for practice on a scientific basis. CRC Press, Boca Raton, pp 486-489

Caccin C, Giacobbo F, Da Ros M, Mariani M (2013) Adsorption of uranium, cesium and strontium onto coconut shell activated carbon. J Radioanal Nucl Chem 297(1):9-18. doi:10.1007/ s10967-012-2305-x

Crittenden JC, Trussel RR, Hand DW, Howe KJ, Tchobanoglouseds G (eds) (2012) Water treatment: principles and design, 3rd edn. New York, Wiley

de Goeij JJM, Bonardi ML (2005) How do we define the concepts specific activity, radioactive concentration, carrier, carrier-free and no-carrier-added? J Radioanal Nucl Chem 263:13-18

Dhir B (2014) Potential of biological materials for removing heavy metals from wastewater. Environ Sci Pollut Res 21:1614-1627

Dulama M, Deneanu N, Pavelescu M, Pasăre L (2009) Combined radioactive liquid waste treatment processes involving inorganic sorbents and micro/ultrafiltration. Rom J Phys 54:851-859

EPA—Strontium website. http://tinyurl.com/ye5y6g4

Ferreira RVDP, Sakata SK, Bellini MH, Marumo JT (2011) Biosorption of Am-241 and Cs-137 by radioactive liquid waste by coffee husk. In: 2011 International Nuclear Atlantic Conference-INAC 2011, Belo Horizonte,Brazil, October 24-28

Fomina M, Gadd GM (2014) Biosorption: current perspectives on concept, definition and application. Bioresour Technol 160:3-14

Fonseca HCO, de Jesus NNM, Nobre VB, Potiens AJ Jr, Sakata SK, (2013) The potential of coconut fibers in raw and treated forms to remove 241Am from aqueous solutions. In: INAC 2013: international nuclear atlantic conference; Recife, PE (Brazil); 24-29 Nov 2013; http://www.iaea.org/inis/collection/NCL CollectionStore/_Public/45/089/45089693.pdf

Fuks L, Oszczak A, Gniazdowska E, Sternik D (2015) Calcium alginate and chitosan as potential sorbents for strontium radionuclide. J Radioanal Nucl Chem 304:15-20

Gładysz-Płaska A, Oszczak A, Fuks L, Majdan M (2016) New effective method for removal of the trivalent Am-241 ions from the drinking water. Pollut J Environ Stud (in press)

Grabias E, Solecki J, Gładysz-Płaska A, Fuks L, Oszczak A, Majdan M (2015) Local minerals for engineering barriers for the national radioactive waste repository (NRWR): sorption of U(VI), $\mathrm{Am}(\mathrm{III}), \mathrm{Sr}(\mathrm{II})$ and $\mathrm{Cs}(\mathrm{I})$ ions on red clay. In: Fuks L (ed) Strategic project "Technologies supporting development of safe nuclear power engineering. Scientific problem no. 4: Development of spent nuclear fuel and radioactive waste management techniques and technologies, INCT, p 112

Gupta VK, Ali I, Saleh TA, Nayak A, Agarwal S (2012) Chemical treatment technologies for waste-water recycling. RSC Adv 2:6380-6388
Hasany SM, Chaudhary MH (1996) Sorption potential of Hare River sand for the removal of antimony from acidic aqueous solution. Appl Radiat Isot 47:467-471

Heuel-Fabianek B (2014) Partition coefficients $\left(K_{d}\right)$ for the modelling of transport processes of radionuclides in groundwater. JÜL-Berichte, Forschungszentrum Jülich (4375) p 11; ISSN 0944-2952

Hideaki M, Tatsuro M, Yasuhiro T Research program on development of advanced treatment technology for americium-containing aqueous waste in NUCEF. JAERI-Tech 96-047, p 33

Ibrahim M, Alaam M, El-Haes H, Jalbout AF, de Leon A (2006) Analysis of the structure and vibrational spectra of glucose and fructose. Eclet Quím 31(3):15-21

Imran A (2012) New generation adsorbents for water treatment. Chem Rev 112:5073-5091

INIS webside. https://inis.iaea.org/search/search.aspx?orig_q=sorption+ AND+radionuclide+water\&src $=$ ics

Jain M, Garg VK, Kadirvelu K (2009) Chromium (VI) removal from aqueous solution, using sunflower stem waste. J Hazard Mater 162:365-372

Järup L (2003) Hazards of heavy metal contamination. Br Med Bull 68:167-182

Kosyakov VN, Veleshko IE, Yakovlev NG (2000) Latest advances in application of chitin-chitosan materials for decontamination of liquid radioactive wastes, 3. In: Russian conference on radiochemistry: Radiochemistry-2000. Abstracts of reports (in russian); http://www.iaea.org/inis/collection/NCLCollectionStore/_ Public/33/026/33026307.pdf

Krejci MR, Finney L, Vogt S, Joester D (2011) Selective sequestration of strontium in desmid green algae by biogenic coprecipitation with barite. Chem Sus Chem 4:470-473

Krejzler J, Narbutt J (2003) Adsorption of strontium, europium and americium(III) ions on a novel adsorbent Apatite II. Nukleonika 48(4):171-175

Liu Y, Liu Y-J (2008) Review: biosorption isotherms, kinetics and thermodynamics. Sep Purif Technol 61:229-242

Liu N, Luo S, Yang Y, Zhang T, Jin J, Liao J (2002) Biosorption of americium-241 by Saccharomyces cerevisiae. J Radioanal Nucl Chem 252(1):187-191

Max JJ, Chapados C (2007) Glucose and fructose hydrates in aqueous solution by IR spectroscopy. J Phys Chem A 111:2679-2689

Miró C, Baeza A, Salas A, Pastor-Valle JF, Pastor-Villegas J (2008) Adsorption of ${ }^{241} \mathrm{Am}$ and ${ }^{226} \mathrm{Ra}$ from natural water by wood charcoal. Appl Radiat Isot 66(1):95-102

Nair KK, Kharb S, Thompkinson DK (2010) Inulin dietary fiber with functional and health attributes-a review. Food Rev Int 26:189-203

Niness KR (1999) Inulin and oligofructose: What are they? J Nutr 129:1402S-1406S

Orth RJ, Kurath DE (1994) Review and assessment of technologies for the separation of strontium from alkaline and acidic media. Report PNL-9053, http://www.iaea.org/inis/collection/NCL CollectionStore/_Public/25/070/25070268.pdf

Oszczak A, Fuks L (2015) Sorption of Sr-85 and Am-241 from liquid radioactive wastes by alginate beads. Nukleonika 60:927-931

Oszczak A, Fuks L, Majdan M (2015) Novel sorbents of natural origin for reprocessing of the low- and medium-level radioactive wastes. In: Fuks L (ed) Strategic project "Technologies supporting development of safe nuclear power engineering. Scientific problem no. 4: Development of spent nuclear fuel and radioactive waste management techniques and technologies, INCT, p. 140 (in Polish)

Puddington IE (1948) The thermal decomposition of carbohydrates. Can J Res 26b:415-431 
Raize O, Argaman Y, Yannai S (2004) Mechanisms of biosorption of different heavy metals by brown marine macroalgae. Biotechnol Bioeng 87:451-458

Rosskopfová O, Galamboš M, Rajec P (2011) Study of sorption processes of strontium on the synthetic hydroxyapatite. J Radioanal Nucl Chem 287:715-722

Schiewer S (1995) Modelling of the proton-metal ion exchange in biosorption. Environ Sci Technol 29:3049-3305

Schütz K, Muks E, Carle R, Schieber A (2006) Separation and quantification of inulin in selected artichoke (Cynara scolymus L.) cultivars and dandelion (Taraxacum officinale WEB. ex
WIGG.) roots by high-performance anion exchange chromatography with pulsed amperometric detection. Biomed Chromatogr 20:1295-1303

Su Y, Yang L, Wang Z, Weng S, Yan C, Wu J (2003) Sugar interaction with metal ion: crystal structure and spectroscopic study of $\mathrm{SrCl} 2 \cdot$ galactitol-4H2O. J Inorg Biochem 94:43-49

Wood CJ, Bradbury D, Elder GR (1998) Regenerative LOMI decontamination process. US Patent 5805654 A

Yildiz S (2011) The metabolism of fructooligosaccharides and fructooligosaccharide-related compounds in plants. Food Rev Int 27:16-50 